Products and Services In Practice is provided to readers using text and images from the manufacturer, supplier or distributor and does not imply endorsement by $B D J$ In Practice. Normal and prudent research should be exercised before purchase or use of any product mentioned.

Please send product and services news through to David Westgarth, BDJ In Practice via: David.Westgarth@bda.org

\section{Simple sterile packaging}

Hygopac View, from Dürr Dental, is an intelligent rotary sealing device, which ensures instruments can be reliably packaged, stored and validated in sterile conditions. Obviously, there is no room for error when it comes to reprocessing instruments that have come into contact with patients' skin, mucous membranes or blood.

Every step in the packaging process must be tested, but also simple to operate, bearing in mind the repetitive nature of such a task. Hygopac View has an intuitive touch display, which takes the operator through the step-by-step process, providing the necessary validation once completed. The sealing temperature, contact pressure and sealing speed are continuously recorded, checked and saved to an SD card or to the network via the VistaSoft Monitor software. This allows effortless processing of the data for documentation within a quality management system. In the event of a practice inspection, the information is available immediately.

As well as offering great flexibility and reliability in terms of process documentation, HygoPac View also boasts an exceptionally efficient design, which is a bonus as it's often used in areas that have limited space.

For more information visit Durr at this year's BDIA Dental Showcase at stand J40.

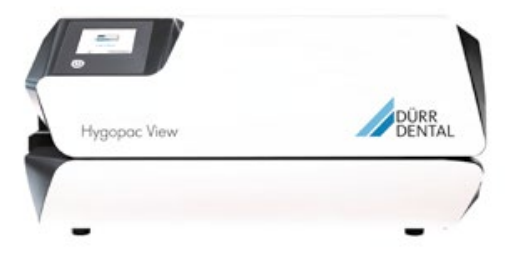

\title{
Get CSR healthy
}

At BDIA Dental Showcase between 1719 October, Dental CSR Certification is delighted to offer dental professionals one-on-one corporate social responsibility (CSR) health checks.

Dental CSR offers a simple set of CSR standards that everyone in dentistry can access and achieve, to help grow their business. Whatever stage you are at with your approach to social and environmental responsibility, there is a straightforward, practical standard that will help you to ensure you are covering the essentials and your business is recognised for it.

During these complimentary halfhour slots, CSR expert Mark Topley will explore with you what you need to do to get certified, offering straightforward, actionable advice.

Whether it's your standards of leadership and team engagement, your community and charity support, or your level of environmental responsibility, Dental CSR Certification standards can help you to measure your performance in this increasingly important aspect of your business.

These appointments are limited in number, so to reserve your date and time, please visit www.calendly.com/marktopley/ healthcheck without delay and choose an available time up to $6 \mathrm{pm}$.

\section{Make a discovery}

As one of the UK's leading dental equipment suppliers, Clark Dental is excited to be exhibiting at this year's BDIA Dental Showcase. The expert team will be discussing and demonstrating the wide range of products they offer, including
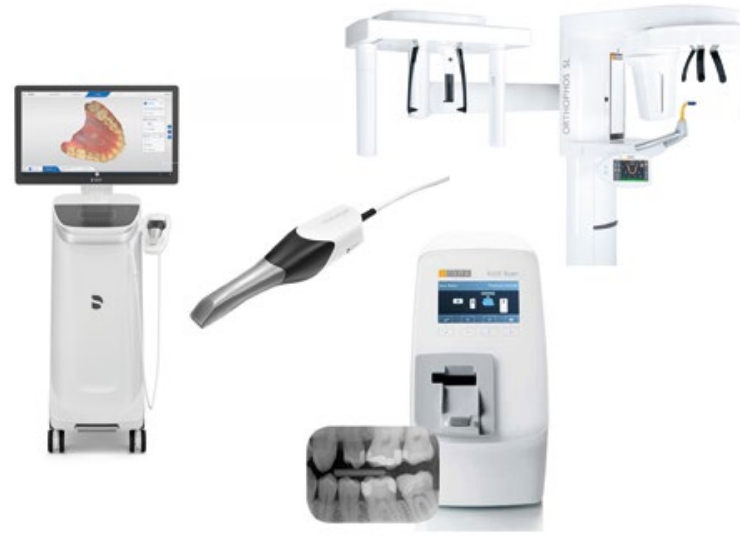

the new Primescan intraoral scanner manufactured by Dentsply Sirona.

Beyond this, delegates can explore the very latest imaging systems supplied by Clark Dental - from the ORTHOPHOS range of $2 \mathrm{D}$ and $3 \mathrm{D}$ systems, to the NOMAD Pro

2 handheld radiographic device. Delegates can also find out how to optimise their practice through Clark Dental's dedicated surgery design service. For more information, call Clark Dental on 01268733 146, email info@clarkdental. co.uk or visit www. clarkdental.co.uk. 